\title{
Beta Fleck formation in Titanium Alloys
}

\author{
K. Kelkar ${ }^{1}$ and A Mitchell ${ }^{2}$ \\ 1. Innovative Research Corp, Plymouth USA \\ 2. University of British Columbia, Vancouver BC Canada \\ alec.mitchell@ubc.ca
}

\begin{abstract}
$\underline{\text { Abstract }}$
Beta fleck is a troublesome segregation defect in many titanium alloys. It has previously been investigated by several authors and appears to have two formation mechanisms, one similar to that of "freckle" in steels and nickel-base alloys, the other arising in the "crystal rain" effect seen in conventional steel ingots. The freckle defect has been extensively studied and several theories developed to account for its formation in both remelted ingots and directional castings. In this work we compare the findings of investigations into the nickel-base freckle formation mechanism to similar conditions in the vacuum arc remelting of titanium alloys. We find that there are strong similarities between the beta fleck formation conditions and the parameters related to the Rayleigh Number criterion for freckle formation. In particular, the dendritic solidification parameters and the density dependence on segregation coefficients both fit well with the conditions proposed to characterise freckle formation. The second formation mechanism arises in the columnar to equiax transition in solidification. The condition for the avoidance of the defect in the two cases is the shown to be the same, namely the use of a very low VAR melting rate, but that it is unlikely to be $100 \%$ successful in preventing defect formation. We propose that the techniques presently in use for alloy development in the superalloy field through optimising the composition for minimum sensitivity to freckle formation should be applied to the formulation of future titanium alloys; also that attention should be paid to developing the PAM process to provide suitable solidification conditions for defect absence in a final ingot.
\end{abstract}

\section{Introduction}

The solute-rich areas found in vacuum-arc remelted (VAR) titanium alloys ("beta fleck") have been investigated by a number of authors (1-7). The level of enrichment causing the change in transformation temperature which leads to defect formation by creating localised beta-rich areas after heat treatment close to the transus temperature depends on the alloy but is generally quite small. The small beta-rich areas are, however, sufficient to cause issues with the mechanical properties of the final product. In alloy production the defect can only be detected by the macro-etching techniques used in quality control. In general, the level of enrichment of the beta-stabilising element (such as $\mathrm{Cr}$ in Ti-17 or Fe in 10-2-3) in the defect area is of the order of +1.5 to $+2 \mathrm{wt} \%$. The precise value of the transus depression caused by varying amounts of alloy elements in 10-2-3 has not been established but based on available data it appears that an increase in Fe content in the amount found in beta flecks would cause a depression of the order of $25 \mathrm{C}$. In other segregation-sensitive titanium alloys the transus depression is relatively similar; in Ti 17 it has been found to be $29 \mathrm{C}$, in Beta CEZ, 16C. The basic problem caused by the defect lies in the nature of VAR processing and is common to segregation issues in other alloy materials, such as "freckle" in superalloys and steels (8) and its relation to the "V" and "A" segregates found in conventionally-cast steel ingots (9). Ingot solidification in the process is progressive and the transients which may cause the solidification defects are short-lived. In consequence, testing the product by macro-etching a radial section at intervals along a billet length cannot 
guarantee freedom from the defect in the regions between the test positions. Melt control in the VAR of titanium alloys is a mature technology but is not capable of eliminating all transient heat-flow events which are thought to be the initiation factor of beta fleck formation. Present techniques of production control rely heavily on information collected from the melt process to indicate if defect-forming events have been present in the melting process. It would be a significant improvement to arrange the ingot-manufacturing process so that the process parameters applied ensure that the conditions leading to the defect are not present, rather than relying on the identification of process instabilities for its detection. In turn, this requirement leads to a need to understand the way in which the defect is formed.

Brookes et al (10) examined an as-cast section of a VAR ingot of alloy 10-2-3 (known to be very sensitive to beta flecks) using unique large-scale SEM/EDAX detection equipment. They showed that the defect was very similar in form to freckles found in VAR ingots of the widely-used nickel-base superalloy, IN718. In IN718 the freckle segregation appears as channels of solute-rich liquid which follow the line of isotherms in the solidifying region at a position where the alloy is approximately $50 \%$ solid. The segregated liquid, which in the IN718 case is denser than the bulk liquid (as is also the case in 10-2-3 and Ti17), flows in a downward direction between the dendrites creating a channel which ultimately solidifies as the freckle defect. (Neither it nor the beta fleck defect can be removed by subsequent heat treatment (1)). The formation mechanism of freckles has been extensively studied $(8,11-17)$. Models have been developed which use the alloy's liquid/solid physical properties and the geometry of the solidifying region to produce a single dimensionless parameter, the Rayleigh Number $(\mathrm{Ra})$ which characterises the probability of a particular solidifying structure to develop freckles. The Ra value represents a balance between the resistance to flow of the dendrite network against the bouyancy-driven flow tendency of the segregated liquid. The condition $\mathrm{Ra}>1$ indicates the possibility that flow will take place. The parameter is then incorporated into models of VAR solidification to establish the melt parameters which would prevent solidification moving into a region where Ra predicts freckle formation. The technique has been used successfully in nickel-base superalloys both to modify VAR process parameters and also to predict ways in which alloy composition may be modified to minimise freckle formation probability (17). A notable feature of the system is the very small changes in liquid density which are required to initiate and maintain a flow system.

Beta fleck composition has been studied (18) in relation to alloy composition in a range of titanium-base alloys. On the basis of the analysis of segregation during the freezing process it was concluded that the fluid flow leading to beta fleck was caused by the movement of segregated liquid corresponding to that remaining when the alloy was approximately $80 \%$ solid. The composition indicates that the remaining liquid density change caused by segregation is positive relative to that of the bulk liquid. (Fig 1). 


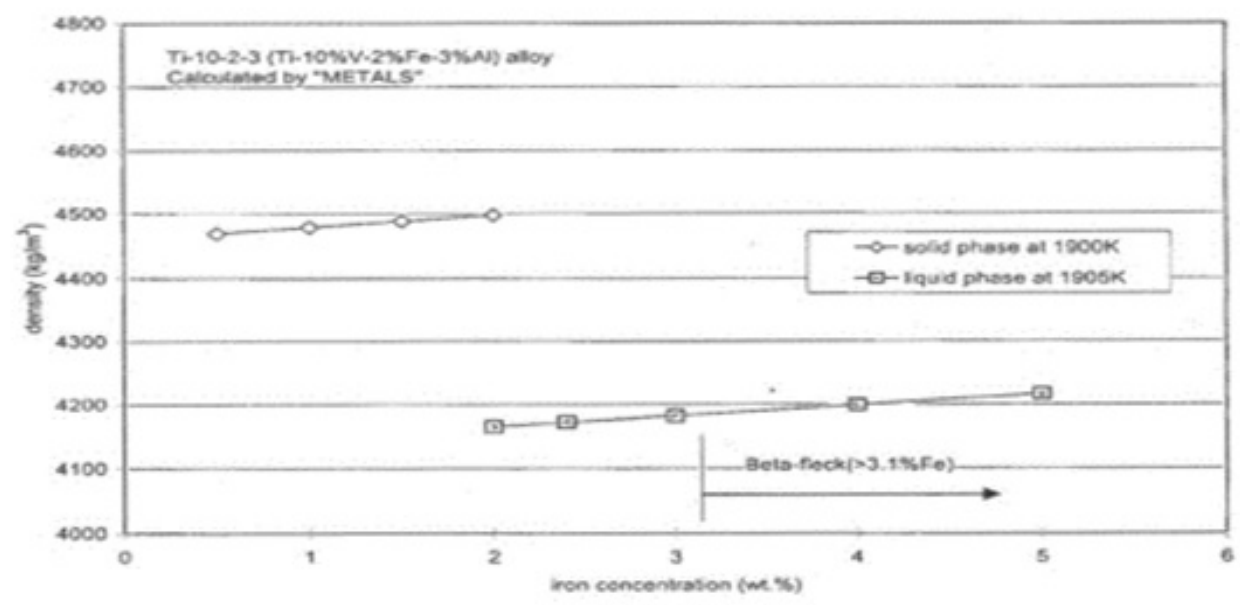

Fig 1(a) Temperature dependence of density for Ti 10-2-3.

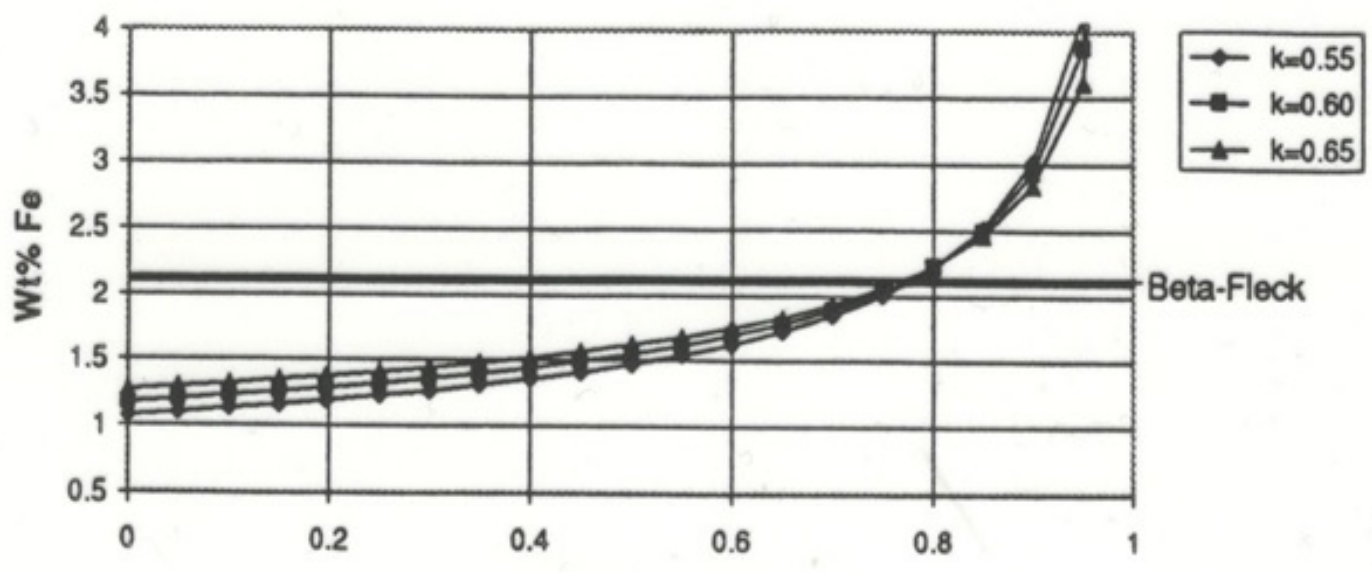

Fraction Solid

Fig 1 (b) Evolution of the remaining liquid composition during solidification

In Ti 10-2-3 using the Scheil relationship.

Examination of the as-cast ingot structure in VAR titanium alloys indicates that the solidification is principally to a columnar dendritic form (19) and so it was concluded that the beta fleck formation mechanism is essentially the same as that found in the nickel-base alloys. However, if the melting/solidification parameters lead to a thermal condition of solidification in which the columnar-dendritic 
structure converts to the equiaxial structure (at the columnar-equiax transition, "CET"), there is the additional possibility that convective movement of the equiaxial crystals (the so-called "crystal rain effect",(9) will permit the collection of segregated liquid in inter-crystalline volumes in the ingot centre. In this case we would expect to find the beta fleck defect occurring only in the ingot central regions. The two mechanisms are not mutually exclusive and could operate simultaneously in the same ingot. In the following sections we examine these propositions and relate them to solidification models of titanium VAR melting.

\section{Solidification and segregation of titanium alloys}

Solidification parameters in titanium alloys are difficult to determine by conventional techniques, partly because of the lack of a suitable refractory container and partly due to the alpha/beta transformation in the solid. The former problem precludes the use of conventional directional solidification techniques and the latter makes a direct determination of the solidification microstructure difficult by using conventional chemical etching. It is clear from experiment however that the alloys solidify in a conventional manner, fast solidification leading to a columnar-dendritic structure which changes to an equiaxial form at lower rates

(26). Typical dendritic structures are shown in Fig $\mathbf{2}$ for alloy material.

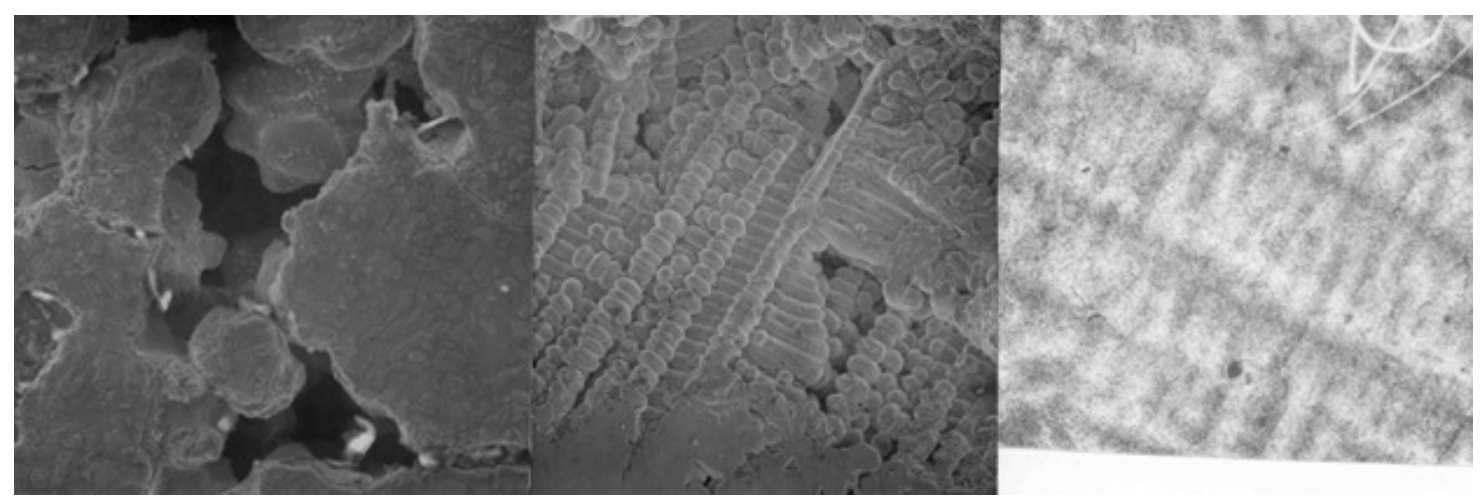

(a)

(b)

(c)

Fig 2. Typical solidification structures of titanium alloys;

$\begin{array}{llll}\text { (a) CP Ti } & \text { (b) Ti 6/4 } & \text { (c) Ti 10-2-3; } & \text { x } 50\end{array}$

The primary and secondary dendrite spacings, which have been measured $(20,21)$ experimentally and also by using computed solidification rates for cast ingots, fall on the same relationship as those for steels and nickel base alloys, Fig (3). 


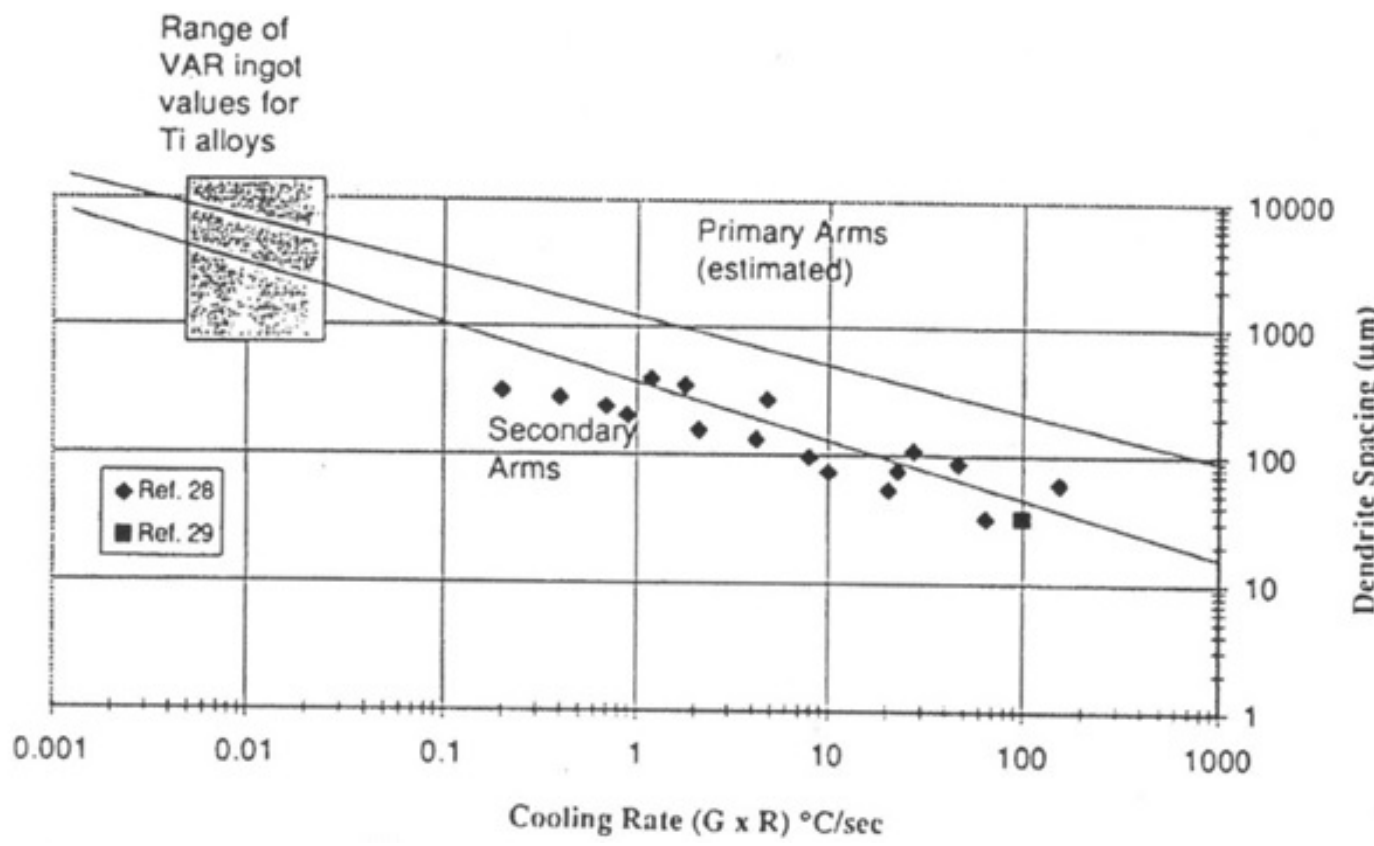

Fig 3; Dendrite arm spacings for Ti alloys in relation to alloy steel systems

This relationship has also been confirmed using the statistical composition scanning method of Nastac (20). It seems therefore reasonable to use the same relationship for the computation of segregation parameters in VAR ingots of titanium alloys as that which has been used successfully for the nickel-base systems.

Segregation parameters for titanium alloys have been measured experimentally, by direct analysis of zone melted samples (21) and by the statistical scanning technique (20). In the case for the present study (that of alloy 10-2-3), the segregation coefficient values are well established both by these experiments and also by computation using phase diagram methods. These parameters are given in Table $\mathbf{1}$.

\begin{tabular}{|l|l|l|l|l|}
\hline liquidus & solidus & K Fe & K Al & K V \\
\hline $1632 C$ & $1595 \mathrm{C}$ & 0.6 & 1.13 & 0.95 \\
\hline
\end{tabular}

Table 1 ; properties of alloy 10-2-3 determined experimentally by Kajikawa (21) 
The remaining physical properties of alloy 10-2-3 have not been experimentally determined. In this computation we have used the known liquid physical properties of alloy 6-4 (22), which we assume to be very similar to those of alloy $10-2-3$.

\section{Computation of the Beta Fleck probability}

The computation method "Meltflow VAR" has been described in the literature (22) and has been validated in numerous studies on steels, nickel-base alloys and titanium alloys. The input in the case of titanium alloys consists of the VAR operating parameters of voltage, current, EMS conditions and geometry together with the physical properties of the alloy concerned, including the segregation and solidification parameters of the alloy. The output comprises the thermal regime of the ingot shown as values not only of temperature but also of liquid metal flow velocities. The output is further processed into dendrite spacings and also, using the structure and segregation values, into a pattern of Ra values throughout the ingot. Typical results are shown in

Figs (4-6) for three values of VAR processing of the alloy 10-2-3 at low, medium and high melting rates.

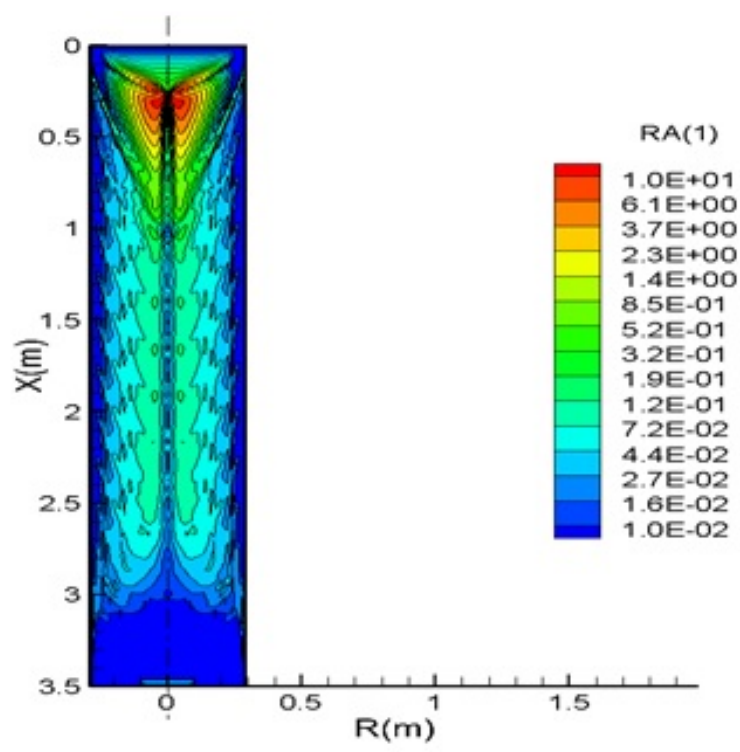

Fig 4 Computed pattern of Ra distribution in a VAR 10-2-3 ingot Ingot $580 \mathrm{~mm}$ dia; electrode $510 \mathrm{~mm}$ dia; $8 \mathrm{Kg} / \mathrm{min}$ melting rate Applied field 40 G, oscillating at 120 sec. 


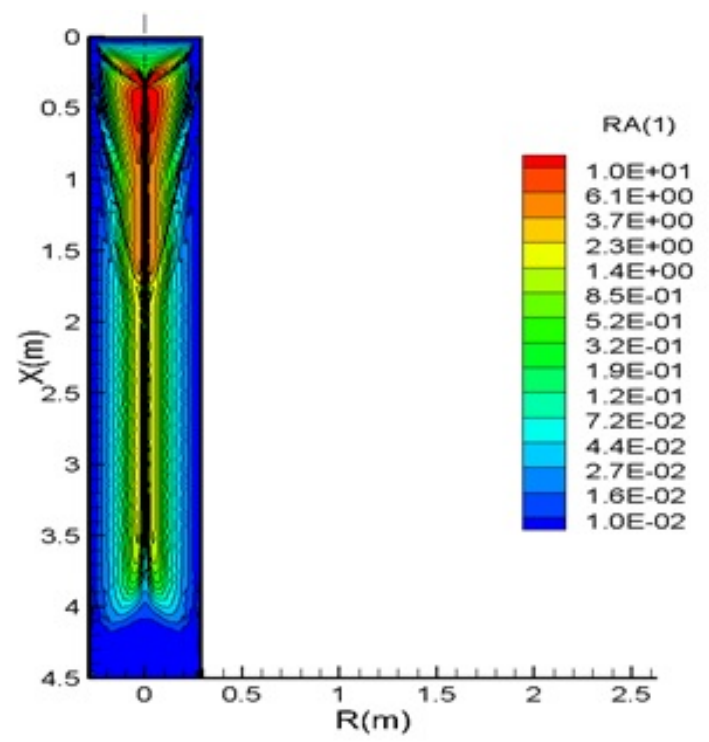

Fig 5; Computed pattern of Ra distribution in a VAR 10-2-3 ingot

Ingot $580 \mathrm{~mm}$ dia; electrode $510 \mathrm{~mm}$ dia; $15 \mathrm{Kg} / \mathrm{min}$ melting rate Applied field 40 G, oscillating at 120 sec.

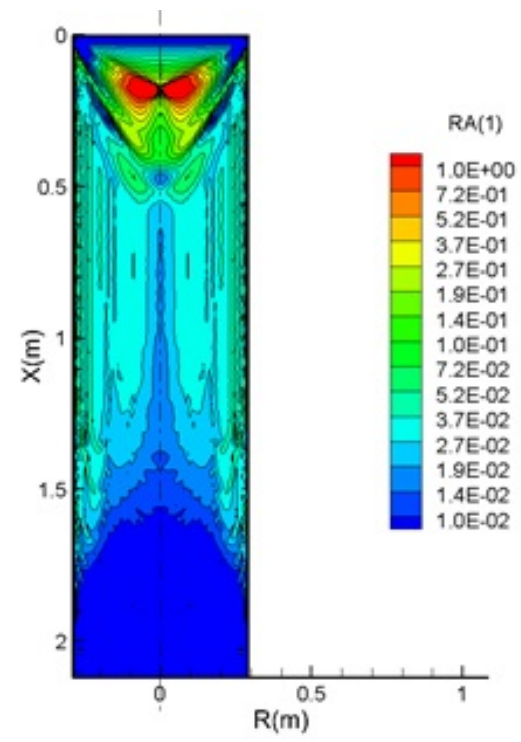




\section{Fig 6; Computed pattern of Ra distribution in a VAR 10-2-3 ingot Ingot $580 \mathrm{~mm}$ dia; electrode $510 \mathrm{~mm}$ dia; $4 \mathrm{Kg} / \mathrm{min}$ melting rate Applied field 40 G, oscillating at 120 sec.}

Several features are of note. The first point is the expected result that there is no probability of beta fleck formation at lowest melting rate where the small primary dendrite spacing does not have sufficient permeability to permit the required fluid flow. At the highest rate, the computation indicates that the ingot would contain beta fleck at essentially all points except the base section where the cooling rate is strongly augmented by the base cooling effect. The cooling rate elsewhere in the liquid/solid region is low enough to provide larger dendrite spacings and hence the permeability needed for interdendritic fluid flow. This finding demonstrates the basis for the commonly-used industrial technique of manufacturing the segregationsensitive titanium alloys in "short fat" ingots. The medium melting rate shows a sensitivity in the ingot top and central portion, leading to the conclusion that by a suitable reduction of melting rate as the ingot progressively grows it should be possible to reduce the probability of formation of the defect. Industrial practice using "programmed" VAR melting rates is an effort to create this situation. However, in order to fully guarantee the absence of the defect, hence making the present billet macro-etch inspection technique valid, the results suggest that for "in-principle" defect elimination it would be necessary to solidify the ingot at a rate which is unacceptably low for manufacturing an ingot with forgeable surface quality by conventional VAR processing.

One result of the composition analysis of beta fleck is that the segregation observed corresponds to interdendritic liquid flow occurring at a position in the solidifying structure when there is approximately $80 \%$ solidification. This value is to be compared with the equivalent value of $50 \%$ in IN718. The segregation parameters of 10-2-3 are not markedly different from those of IN718 and the negative buoyancy force driving the interdendritic flow is quite similar in both alloys. The difference may arise in the precipitation of primary carbides $(\mathrm{NbC})$ in IN718 which becomes significant at the 50\% solidification value, thus significantly increasing the remaining liquid density by removing carbon. The carbide particles also would decrease permeability and hinder flow at lower temperatures and hence by default, the liquid which forms freckles would then come from the $50 \%$ value. There are no primary precipitates in the titanium alloys and the gradual increase in liquid density due to segregation consequentially only reaches the required "flow" value at the $80 \%$ solid level. Using the data given by Kawakami (22) the liquid density gradient between the bulk liquid of 10-2-3 and the analysed beta fleck composition is $0.66 \mathrm{Kg} \cdot \mathrm{m}-3 . \mathrm{K}-1$. Following the analysis of flow conditions given by Auburtin (15) the minimum density gradient required for flow to form freckles in IN718 is approximately $0.3 \mathrm{Kg} \cdot \mathrm{m}^{-3} \cdot \mathrm{K}^{-1}$ over the range of primary dendrite spacings between 200 and 400 microns. Although there is insufficient data on the physical properties of 10-2-3 to make a precise correlation between the two alloys it appears likely that the density gradient calculated for segregation in 10-2-3 is adequate for the defect-forming flow to occur in the ingot cross-sectional dimensions generally produced in VAR. Using the analytical method developed by Kajikawa(17) we may make a comparison of the freckling tendency of 10-2-3 as compared to that of a number of nickel-base alloys shown in Fig 7. 


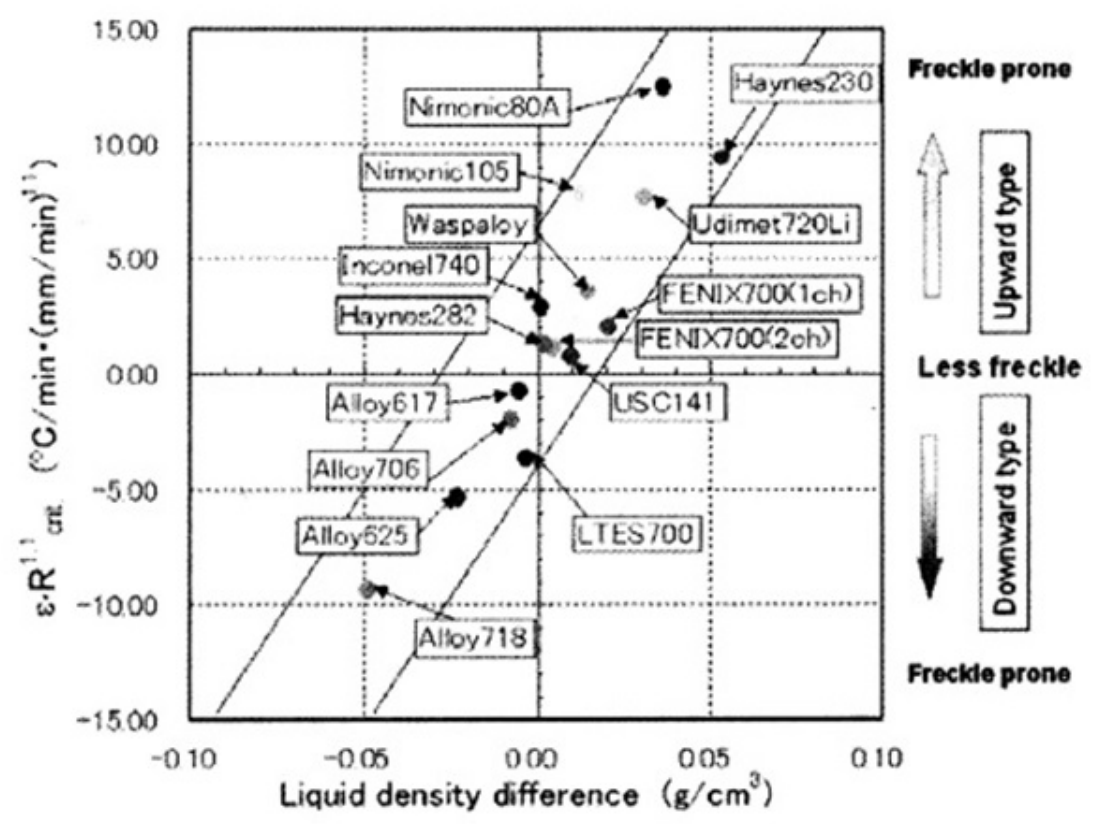

Fig 7; Sensitivity of various alloys according to Kajikawa (17)

It is clear from the above analysis that 10-2-3 presents a difficulty in VAR manufacture which is close that that experienced in remelting IN718. In the latter alloy, production of high quality material is limited to VAR ingots of approximately $600 \mathrm{~mm}$ diameter and melting rates in the range $3.5-4 \mathrm{Kg} / \mathrm{min}$, although ingots as large as $750 \mathrm{~mm}$ have been produced with difficulty in aerospace grades.

Kajikawa (17) suggests that the freckling tendency should be used as a guide to the modification of alloy composition in order to reduce the freckle incidence in ingots. The technique is a manipulation of the alloy composition so that the segregating interdendritic liquid has a density relative to the bulk liquid which is too small to sustain the channel flow. The principle has been shown to be advantageous in controlling the properties of alloy 6/4 and hence may be acceptable in 10-2-3.

Examination of the as-cast structure of VAR ingots of CPTi has been reported (23) and shows that the outer radial regions of the ingot section have a columnar dendritic form. The central regions show equiax crystals, demonstrating that the solidification conditions have caused the solidifying structure to cross the CET region of the diagram shown in Fig 8. 


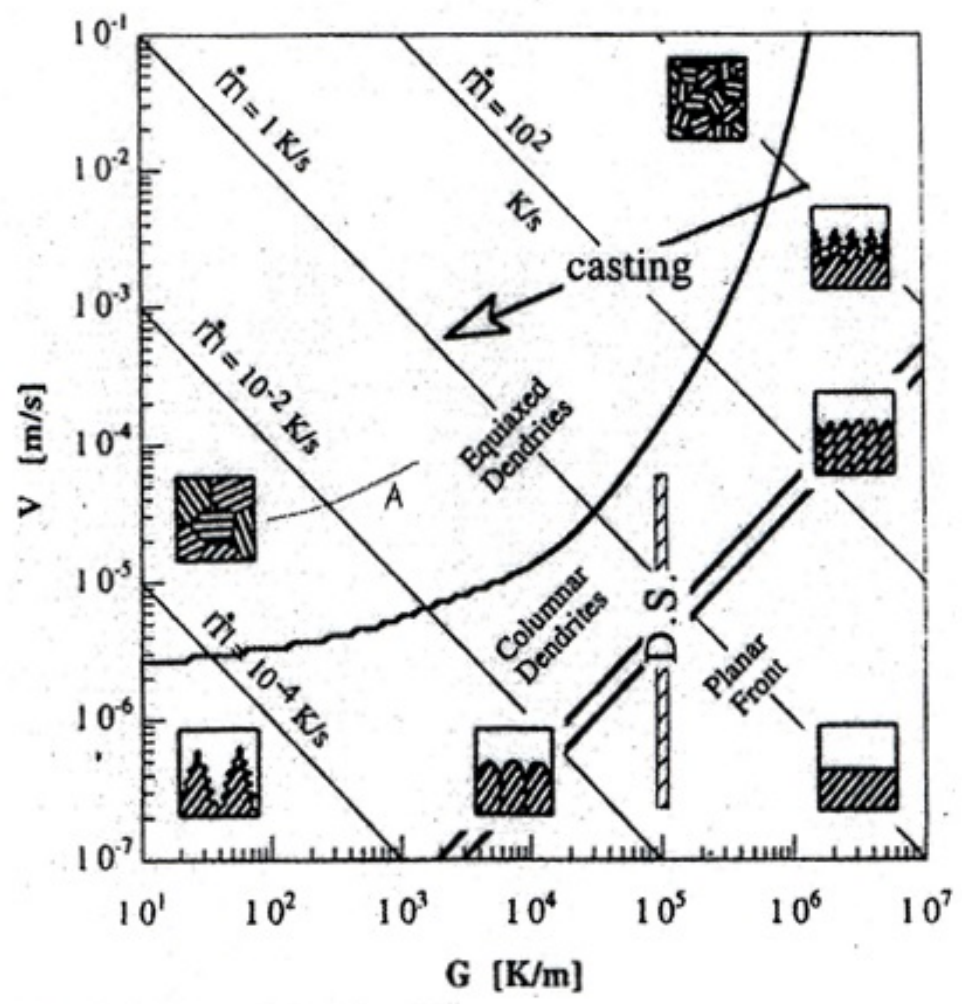

Fig 8; Solidification diagram (23); line ' $A$ ' is the experimentally determined CET boundary for Ti alloys,

The melting parameters used for CPTi are, however, significantly different to those generally applied to higher alloy compositions with higher power being applied in the VAR process. Similar examinations of industrial VAR ingots of alloy 6-4 indicate that the structure is entirely columnar dendritic. There are no report results for VAR ingots of 10-2-3, but the sections shown by Brookes (10) are fully columnar dendritic in nature. It appears probable that at the very low melting rates used for the beta-fleck sensitive titanium alloys, the solidification conditions of the ingot central region do not lead to the structure parameters crossing the CET boundary, as is seen from Fig 8 . In this case, the proposed defect formation mechanism of "crystal rain" would not apply.

\section{Relation to Industrial Practice}

The practical finding from VAR processing of segregation sensitive titanium alloys (also with an equivalent in nickel-base processing) is that the defect formation in the Ra probability zone appears to be initiated by melting instability through irregular arc movement or sudden changes in the flow regime and/or in the heat transfer conditions. It has been held that these instabilities cause sharp changes in liquid flow within the interdendritic region and hence initiate the flow which produces the defect by de-stabilising the inverse density gradient in the liquid. (It should be noted that the computed Ra value does not indicate that the flow 
will certainly take place but only that if the appropriate flow is initiated, it will grow into a defect). However, work on the flow regime which exists during the columnar dendritic solidification of steels showed (24) that the penetration depth of momentum transfer from bulk liquid into the interdendritic region was quite small. The results showed that even when the bulk liquid was moving at $1 \mathrm{~m} / \mathrm{s}$ the consequent motion of interdendritic liquid was already reduced to zero at the $30 \%$ solid position for primary dendrite arm spacings of $300-500$ microns. The liquid velocities near the liquidus interface in VAR titanium alloys as computed by "Meltflow VAR" are less than an order of magnitude of this value. This finding cannot be reconciled with the proposal that perturbations in the bulk liquid initiate the interdendritic flow at a point where the region has reached $80 \%$ solid. The initiation mechanism for the beta fleck flow is hence still not established, indicating that the only known technique to prevent its presence is to solidify the ingot in a regime where the Ra values indicate a zero probability for its formation even if initiation events are present. The principal disadvantage of the VAR process is that the ingot solidification rate cannot be controlled independently from the melting rate of the electrode. When combined with the requirement to use a sufficiently high power input to produce an acceptable ingot surface this condition imposes a practical minimum solidification rate at all points in the ingot. This minimum rate is directly proportional to the diameter of the ingot. The practical minimum values of process parameters in making VAR ingots in the diameter range of $500 \mathrm{~mm}$ and larger, places the solidification conditions into a range where the Ra values are greater than unity over much of the ingot and hence where defect formation is possible. Measures are taken in the procedures (such as triple melting) to minimise the incidence of the putative initiation events, but the random occurrence of the defect appears to be inevitable in existing practice. Chen (.25) studied the practicality of using 10-2-3 material which contained beta fleck in large forgings for aerospace application. It was found that by suitable manipulation of both heat treatment temperatures and forging practice adequate properties could be obtained. The beta fleck regions exhibited transus depressions of up to $42 \mathrm{oC}$ and it was also observed that the transus depression of the beta fleck region was a function of ingot size. Although present practice follows this general route of attempting to minimise the beta fleck problem it would clearly be more satisfactory to have ingots which did not contain the defect.

The solution to the above problem lies in devising a process in which the power input and ingot solidification conditions are de-linked. Such a process would then allow sufficient power input to provide for a good surface condition whilst allowing for high solidification thermal gradients in the ingot. The existing processes which could fulfill this condition are electron beam cold hearth melting (EBCHM) and plasma arc melting (PAM). The former process is presently in use for the manufacture of 6-4 alloy but has the disadvantage of requiring high vacuum conditions for its operation and hence is not a practical solution for the manufacture of alloys with significant content of more than one volatile element e.g.10-2-3. The PAM process operates at pressures closer to atmospheric and hence does not have the disadvantage of composition control. It is, however, a highly complex process from a mechanical aspect and has so far not been extensively used to make "final product" alloy ingots. Nonetheless, from the viewpoint of in-principle feasibility PAM offers the most probable solution to this problem. A further, more distant possibility lies in the use of induction skull melting (ISM). Large diameter ISM systems have been designed and would produce the alloy ingots required albeit with a large power input requirement. The unknown factor in such a development is the influence on the solidification structure of the high liquid velocities existing at the solidification interface as a result of the electromagnetic regime in the process. The result would probably be a fine-grained equiaxial structure, possibly bringing mechanical working issues which are presently unknown. 


\section{Conclusions}

The above results outline the methods required for the determination of the required solidification conditions for the elimination of beta fleck in titanium alloys as related to the production of industrial ingots. Due to the restrictions created by the volatility of the alloy components in most titanium alloys the only presently-used process in which the low melting rate required in making large ingots could achieved with good ingot surface quality is PAM. This conclusion indicates a need to re-consider the place of PAM by upgrading it to a final product producer, not simply as an electrode manufacturing method; or alternatively by using it as a second melt process. In this way we could bring titanium alloy ingot manufacture into a regime where the formation of beta fleck is no longer an issue.

\section{$\underline{\text { References }}$}

1 C.E.Shamblen;"Minimising Beta Flecks in the Ti17 Alloy", Met Trans B, 28B, (1997), pp899-909

2 Z.Weldong, Z Yigang, and Yu Hanqing; "Effect of Beta Flecks on Low-Cycle Fatigue Properties of Ti-10V2Fe-3Al Alloy", J. Materials Engineering and performance, 9(2), (2000), pp222-232

3 Z Xingdon "Beta Flecks in Ti17 Alloy", J Titanium Industry Progress, 28(4), (2011), pp417-422

4 Z Yigang "Effect of Beta Fleck on Mechanical Properties (Low Cycle Fatigue)", Acta Met Sinica, 28(12), (1992), pp560-573.

5 D Li, S-X Hui, W-J Ye and C-L Li, "Microstructure and mechanical properties of a new high-strength and high toughness titanium alloy”, J Rare Metals, (2016), pp1-7

6 V V Tetyukin, V N Kurapov and Y P Denisov, "Segregation and phase heterogeneity in titanium ingots and semi-finished products”, Proc.”Titanium '80” Kyoto (1980), pp2117-2128

7 Z Yang, H Kou, J Li, R Hu, H Chang and L Zhou, "Macro Segregation Behaviour of Ti-10V-2-Fe-3Al Alloy during Vacuum Consumable Arc Remelting Process", J Materials Engineering and Performance", 20(1), (2011), pp65-70.

8 S M Copley, A F Giamei, S M Johnson and M F Hornbecker, "The Origin of Freckles in Unidirectionally Solidified Castings" Met Trans, 1, pp2193-2204

9 J J Moore and N A Shah, "Mechanisms of Formation of A and V segregates in Cast Steel", Int. Met Rev, 28(6), (1983), pp338-355.

10 J A Brookes, J S Krafcik, J A Schneider, J A VanDenAvyle, and F Spadafora, "Fe Segregation in Ti-10V2Fe-3Al 30 inch VAR Ingot B-fleck Formation”, Proc Int Symp on Liquid Metals Processing and Casting, (1999), pp130 - 145

11 P Auburtin, "Determination of the Effect of Growth Front Angle on Freckle Formation", PhD Thesis Univ of British Columbia, (1998)

12 H Combeau, G Lesoult, "Simulation of Freckle Formation and Related Segregation during the Directional Solidification of Metallic Alloys", Modeling of Casting, Welding and Advanced Solidification processes VI, ed T S Piwonka et al, publ TMS New York (1993), pp201-208.

$13 \mathrm{~S}$ Asai and I Muchi, "Theoretical Analysis and Model Experiments on the Formation Mechanism of Channel Segregation”, Trans ISIJ, 18, (1978), pp90 - 98

14 M S Bhat, D R Poirier and J C Heinrich, "Permeability for Cross-Flow through Columnar-Dendritic Alloys", Met Trans B, 26B, (1995), pp1049 - 1056

15 P Auburtin, S L Cockcroft and A Mitchell, "Liquid Density Inversion during the Solidification of Superalloys and its Relationship to Freckle Formation in Castings" Superalloys (1996), publ. TMS New York 1996, pp443 - 450. 
16 M C Schneider, J P Gu, C Beckermann, W J Boettinger and U R Kattner, "Modeling of Micro- and Macro-Segregation and Freckle Formation in Single Crystal Nickel-Base Superalloy Directional Solidification", Met Trans A, 28A, (1997), pp1517 - 1531.

17 K Kajikawa, M Tanaka, S Suzuki and H Yamada, "Freckling Tendencies of A-USC Candidate Ni-Based Superalloys" Proc IFM (2011), pp219 - 223.

18 Kawakami A. Mitchell, and S L Cockcroft: "Segregation in Titanium Ingots", J High Temperature Materials and Processes, 26 (1), (2007) 59 - 79

19 A Kawakami and A Mitchell: “Solidification and Segregation in Titanium Alloys” Proc Ti2007 Conference, Kyoto Japan (2007), publ. Japan Titanium Society, Tokyo 159 - 166,

20 L Nastac, J Chou and Y Pang, "Assessment of Solidification Kinetics Parameters for Titanium Alloys" Proc Int Symp on Liquid metal Processing and Casting 1999, publ AVS, (1999), pp207 - 224.

21 A Kawakami, "Study of Solidification and Segregation in Titanium Alloys" MASc Thesis University of British Columbia (2002).

22 K Kelkar, S Patankar, A Mitchell, O Kanou, N Fukada and K Suzuki: "Computational Modelling of the VAR process for the Production of Ingots of Titanium Alloys" Proc "Ti 2007 Conference", Kyoto Japan (2007), publ. Japan Titanium Society, Tokyo 159 - 166,

23 A Mitchell, "Industrial Effects of Columnar/Equiax Transition in Remelted Ingots" International Journal of Cast Metals Research, (2009), 22, pp1-4.

24 K Sasaki, Y Sugitani, S Kobayashi and S Ishimura, "Interdendritic Fluid Flow during Columnar Solidification of Steels", ISIJ, (1979), 65, pp 60-69

25 C C Chen and R R Boyer; "Practical Considerations for Manufacturing High-Strength Ti-10V-2Fe- 3Al Alloy Forgings", Journal of Metals, July, (1979), pp 33 - 39.

26 A Mitchell; "Industrial Effects of the Columnar to Equiax Transition", Journal of Cast Metal Research, (2009), 22, pp 1-8. 